Article

\title{
The Force Is Strong with This One (but Not That One): What Makes a Successful Star Wars Video Game Adaptation?
}

\author{
Matthew Barr (10) \\ School of Computing Science, University of Glasgow, Glasgow G12 8RZ, Scotland, UK; \\ Matthew.Barr@glasgow.ac.uk
}

Received: 24 September 2020; Accepted: 7 December 2020; Published: 16 December 2020

\begin{abstract}
The Star Wars films have probably spawned more video game adaptations than any other franchise. From the 1982 release of The Empire Strikes Back on the Atari 2600 to 2019's Jedi: Fallen Order, around one hundred officially licensed Star Wars games have been published to date. Inevitably, the quality of these adaptations has varied, ranging from timeless classics such as Star Wars: Knights of the Old Republic, to such lamentable cash grabs as the Attack of the Clones movie tie-in. But what makes certain ludic adaptations of George Lucas' space opera more successful than others? To answer this question, the critical response to some of the best-reviewed Star Wars games is analysed here, revealing a number of potential factors to consider, including the audio-visual quality of the games, the attendant story, and aspects of the gameplay. The tension between what constitutes a good game and what makes for a good Star Wars adaptation is also discussed. It is concluded that, while many well-received adaptations share certain characteristics—such as John Williams' iconic score, a high degree of visual fidelity, and certain mythic story elements-the very best Star Wars games are those which advance the state of the art in video games, while simultaneously evoking something of Lucas' cinematic saga.
\end{abstract}

Keywords: video games; game studies; adaptation; Star Wars; George Lucas; game reviews; criticism; thematic analysis

\section{Introduction}

For this Star Wars fan, Atari's 1983 Star Wars arcade machine, replete with its cutting-edge vector graphics and digitised movie sounds effects, remains a formative experience. Alongside certain later adaptations-Super Star Wars (Sculptured Software, Inc. and LucasArts Entertainment Company LLC 1992), Star Wars: Knights of the Old Republic (BioWare Corporation 2003), and Star Wars: Rogue Squadron (Factor $5 \mathrm{GmbH}$ 1998) — the original arcade game represents a high-water mark for gaming in a galaxy far, far away. These are personal favourites, of course, dictated by circumstance and tinged with nostalgia. For others of my generation, perhaps Star Wars: X-Wing (LucasArts Entertainment Company LLC 1993) and its sequels are the pinnacle of the films' numerous video game renditions. The Maker only knows what Millennials, raised on the turgid cinematic prequels, might consider the quintessential Star Wars game: perhaps Star Wars Episode I: Racer (LucasArts Entertainment Company LLC 1999) is their equivalent of the Star Wars arcade cabinet. But what do these lauded adaptations of the filmic saga have in common? With around one hundred officially licensed Star Wars video game titles released to date ${ }^{1}$, and many of these already consigned to memory's garbage compactor, why do

1 https://en.wikipedia.org/wiki/List_of_Star_Wars_video_games. 
some ludic adaptations of Lucas's space opera stand the test of time? In short: what makes a good Star Wars video game?

The late and much lauded American film critic, Pauline Kael, famously stated that "movies are good at action; they're not good at reflective thought or conceptual thinking" (Naremore 2000, p. 59). While the assertion that film cannot portray or inspire reflection is dubious, the implication here is that something is lost in the adaptation of a literary text to film. Video games, on the other hand, embody action; this is a medium often marked by its active (and interactive) nature. Thus, it might be expected that a video game adaptation of an action-heavy movie franchise such as Star Wars has the potential for excellence, to capture the essence of the original material. Indeed, Kael went on to say of movies that, "they're good at immediate stimulus"; likewise, video games are frequently described-and sometimes derided-as providing short-term stimulation and little else. This is nonsense, of course: games, like film, are an affective medium (see Ramsay 2020, for example), capable of transcending such ill-informed characterisations. But perhaps the undeniable synergies between the two media might render the process of adaptation from movie to game more straightforward than, say, adapting literature to film. As noted by Hutton and Barr (2019), video game adaptations of great literary works are relatively scarce, for example, despite the increasing visibility of games in the study of adaptation.

Perhaps the relative abundance of movie adaptations is a consequence of the characteristics they share with video games, as distinctly audio-visual forms. Or, maybe, there is simply little commercial imperative to develop video game adaptations of literary works, with no suitably lucrative opportunities for cross-promotion. In fact, direct adaptations of the Star Wars movies have typically fared less well with critics than more original titles, falling foul of the rule that dictates that movie tie-ins must exist only to satisfy capitalist desires, and not to enlighten or entertain. Star Wars Episode II: Attack of the Clones for the Game Boy Advance (David A. Palmer Productions 2002) effectively illustrates this point, with Electronic Gaming Monthly's exasperated reviewer describing the movie tie-in as "one of the worst games I've ever played" (Electronic Gaming Monthly 2002). A grievous sin, indeed, for a game based on such a revered action movie franchise.

While Attack of the Clones may represent something of a nadir for Star Wars video games, the question of what makes a good adaptation may be explored by examining the better reviewed games to be released under the Star Wars moniker. To this end, we can look to the review aggregator website, Metacritic, which has conveniently compiled a list of the most critically lauded Star Wars titles for the 20 years to $2017^{2}$. For the purposes of this work, we will consider the top five entries on this list, as reproduced in Table 1.

Table 1. The top five Star Wars games for the 20 year to 2017, according to Metacritic and ranked by 'metascore'.

\begin{tabular}{cccc}
\hline Rank & Title & Year & Metascore \\
\hline 1 & Star Wars: Knights of the Old Republic & 2003 & 94 \\
\hline 2 & Star Wars Jedi Knight: Dark Forces II & 1997 & 91 \\
\hline 3 & Star Wars Rogue Leader: Rogue Squadron II & 2001 & 90 \\
\hline 4 & Star Wars Jedi Knight II: Jedi Outcast & 2002 & 89 \\
\hline 5 & Angry Birds Star Wars & 2012 & 88 \\
\hline
\end{tabular}

Metacritic scores are an imperfect approach to determining quality, of course, not least because the nuances of the text that accompanies each review are lost. Furthermore, the published scores are not straightforward mean values; the review aggregator employs an opaque weighting algorithm to calculate the Metacritic score based on an assessment of each reviewers' critical clout. Given

2 https://www.metacritic.com/pictures/best-star-wars-video-games-ranked/. 
its web-based origins, Metacritic also tends to represent older titles-those which were reviewed predominantly in print-less comprehensively. Millennials may well express affection for Star Wars Episode I: Racer, released to coincide with the arrival of The Phantom Menace (Lucas 1999) and, indeed, the venerable Nintendo Power magazine awarded the game a robust 8/10 score in its original review. However, despite falling within the timeframe for inclusion in Metacritic's report, the paucity of Episode I: Racer reviews-at least as far as the review aggregator is concerned-means that the game falls beneath the threshold for calculating a Metacritic score at all.

It is worth noting, too, that the Metacritic report was published in 2017. Nevertheless, the only significant Star Wars game released since then is Star Wars Jedi: Fallen Order (Respawn Entertainment LLC 2019), which currently enjoys a Metacritic score of 81 on Xbox One and PC. Star Wars Battlefront II, released in 2017, languishes a few parsecs behind with a mean Metacritic score of 66 across the three platforms on which it was released. For context, the remainder of Metacritic's top ten includes several series that already feature in the top five: Star Wars: The Old Republic (BioWare Austin, LLC 2011) [Metacritic score 85], Star Wars: Knights of the Old Republic II: The Sith Lords (Obsidian Entertainment, Inc. 2004) [86], and Star Wars: Rogue Squadron (Factor 5 GmbH 1998) [85]. Somewhat unexpectedly, the top ten also includes two Episode 1 spin-offs: Star Wars: Episode I Battle for Naboo (LucasArts Entertainment Company LLC 2000) [84] and Star Wars: Starfighter (LucasArts Entertainment Company LLC 2001) [84]. It is fair to say, however, that the design of these latter titles is firmly rooted in the conventions laid down by the Rogue Squadron games, already accounted for in the top five.

The focus of this paper, then, is on the critical response to apparently successful Star Wars adaptations. As such, the analysis must be considered within the wider context of games journalism, a vocation that, according to Foxman and Nieborg, lacks a "common set of shared professional values", with game critics relying instead on their "personal background" to inform their criticism (Foxman and Nieborg 2016). More problematic is Nieborg and Sihvonen's suggestion that games journalists act as little more than an extension of game publishers' marketing departments; this despite individual journalists' anxieties about their symbiotic relationship with the industry they purportedly exist to critique (Nieborg and Sihvonen 2009). Consalvo presented an equally denigratory view of games publications, noting that "many have been derided as nothing more that either public relations rags for the game industry or fanboy publications that lack serious journalism" Nieborg and Sihvonen (2009, p. 37).

However, while scholars may question the integrity of games criticism, it is clear that not every release is greeted with slavish enthusiasm; certainly, those Attack of the Clones reviews will have shifted very few units for the publisher. Furthermore, it is entirely possible to discern which aspects of the games reviewers felt warranted praise. This is useful in itself, as we attempt to determine what makes these Star Wars adaptations better than others, even if the reviews are unduly effusive. So, what follows is a broad thematic analysis of the reviews for each of the five games named above. Based on these reviews, a number of themes are identified in relation to the qualities of each adaptation, including the games' visuals, audio, gameplay, and story.

\section{Who's Scruffy Looking?}

Reading through the reviews of each of these adaptations, it is difficult not to be struck by the emphasis critics place on the visual qualities of the games. Perhaps adding grist to Pauline Kael's mill, the impressive nature of the original movie's visual effects was similarly emphasised in the reviews of the time, with legendary Chicago Tribune movie critic Gene Siskel stating in his 1977 review of the film that "Star Wars is not a great movie in the sense that it describes the human condition. [ ... ] What places it a sizable cut above the routine is its spectacular visual effects" (Siskel 1977). It is reasonable to assert, then, that dazzling visuals and technically impressive effects have always been a part of what defines Star Wars. 
The games are no exception, with many reviews praising the visual fidelity on display: "Graphically, Jedi Outcast is fantastic" (Butts 2002); "From a graphics perspective the game is gorgeous" (Stevenson 2003); "It goes without saying that the first thing you'll notice about Rogue Leader is the game's amazing graphics" (Bedigian 2001); "the game's graphics are stupendous, amazing, superb, and outstanding - choose your favorite" (Casamassina 2001).

This critical praise generally falls into one of two categories: admiration for the underlying technical achievements or delight at the degree to which the look of the movies has been recreated. The discussion of the former quickly, and perhaps inevitably, descends into hyperbole-inflected technical jargon. In the GameSpot review of Rogue Leader, for example, Ricardo Torres framed the developers' visual achievements in terms of their mastery of the hardware on which the game runs:

"Making use of nearly every bell and whistle that the GameCube hardware has to offer, Rogue Leader is a jaw-droppingly gorgeous game. All craft in the game feature extremely generous polygon counts that are enhanced by special effects such as bump mapping, self-shadowing, and high-resolution textures." (Torres 2001)

The IGN review of the same game also beheld beauty in the developers' technical prowess, again expressed in terms of polygon count and computationally expensive visual effects:

"Polygons are pushed well into the millions to form some of the most detailed ship and character models, and everything is exquisitely lit and shadowed by the artists. But there are also crazy real-time lighting effects, casting shadows and self-shadowing objects. And every texture seems to be bump-mapped, or dirt-mapped, or reflection-mapped—or whatever." (Casamassina 2001)

Noting with excitement that "blaster explosions are all light-sourced", the Adrenaline Vault review of Dark Forces suggested that the game demands to be played using the latest hardware technology:

"It seems obvious that the graphics in this game are exceptional. Although a 3D-accelerated card is not necessary for playing Jedi Knight, the full effect cannot be appreciated without such technology. Even so, the graphics in this game will probably be the best you have ever seen displayed on your system." (Brumbaugh 1997)

While it is clear that games may be appreciated simply for their capacity to harness technology in the service of art, there is an additional dimension to consider where the object is to recreate another visual form. As the reviews analysed here demonstrate, the effectiveness with which video game adaptations can reconstruct the visual flavour of the movies is an important factor to consider.

As Keiron Gillen remarked in his Eurogamer review of Rogue Leader, "visually this is Star Wars as you saw it on the big screen". Describing that game as "one of the most visually impressive videogames ever created", the Cinescape review of the GameCube classic also alluded to a film-like visual experience:

"Factor 5 has managed to faithfully recreate the movies. They've provided hundreds of TIEs on screen with no slowdown, lighting effects to the maximum, and some visuals that are so reminiscent of the films that you'll do a double take. Rogue Leader is a sensory barrage." (Stevenson 2001)

Writing for GameZone, Louis Bedigian was equally effusive about developer Factor 5's ability to capture the visual flair of the movies:"The Star Wars universe is represented with startling near perfection to the movies we all know and love so much." (Bedigian 2001).

Rogue Squadron is far from the only game considered here to have been acclaimed for its graphical fidelity to the movies. The Gaming Age review of Dark Forces, for example, remarked that our favourite characters were rendered and animated in such detail that they "look like their movie counterparts". The GamePro review of Jedi Outcast (Raven Software Corporation 2002) also conveyed the aesthetic pleasures of seeing the familiar elements of the original trilogy rendered in such recognisable detail: 
"Visually, Jedi Outcast looks amazing. Everything is as Star Wars as it should be; droids shamble and shine, stormtroopers flip and dance when they get shot, and blasters spurt color-coded beams across the battlefield. You'll recognize TIE fighters in their hangar and grin with satisfaction as a realistic-looking Lando Calrissian greets you from his prison cell." (Darth Destroyer 2002)

As noted, several of these reviews alluded to the significance of the hardware on which the games run, in relation to that hardware's graphical capabilities. In referring to Rogue Leader's use of the GameCube's "every bell and whistle", Torres, for example, was gesturing towards that game's status as a launch title-and graphical showcase-for the new Nintendo console. Others referred directly to the ever-evolving specifications of PC graphics cards. This paper is not positioned within the recent tradition of platform studies, as set out by Bogost and Montford (2007) and expanded upon by scholars including Apperley and Jayemane (2012). However, a more holistic view of these games' critical reception would necessarily include some consideration of the cultural and technological context in which they were released. Apperley and Parikka (2015) discussion of platform studies and media archaeology asked whether the significance of a gaming platform may be fully understood without taking into account the success of its launch titles. By corollary, might it not also be the case that the circumstances of a game's critical and commercial reception may only be understood in relation to the platform on which it is released?

\section{Will You Shut Up and Listen to Me?}

As the Cinescape review of Rogue Leader noted, audio plays arguably just as important a role in evoking Star Wars as the visuals might, "besides killer gameplay and graphics, what else can you expect from a Star Wars game? Killer music and sound effects" (Stevenson 2001). Apparently, the sounds and visuals are indelibly linked in many critics' minds, as the Eurogamer review illustrates:

"Scenes from the films are remodelled in the crisp game engine and look almost perfect, accompanied by John Williams' inimitable score and virtually any of the films' sound effects you might care to mention."

Both John Williams' iconic score and the instantly recognisable sound effects created by Ben Burtt and the team at Industrial Light and Magic seem integral to any successful video game adaptation of Star Wars. As the GameZone review of Jedi Outcast put it, "The music just never gets old. The crackling slash of sabers just never gets tired" (RGerbino 2002). Meanwhile another critic made clear their expectations when it comes to the aural quality of a Star Wars title, "Of course, Jedi Outcast's sound is perfect, but, with this being a Star Wars game, you knew that already" (Darth Destroyer 2002). The GameZone review of Jedi Outcast, however, provided a more nuanced justification for these high expectations:

"The sounds within the game put you right into Kyle's shoes. Once you hear the familiar sound of your saber you will fall in love. John Williams' music once again consumes every ounce of emotion whether you are sneaking around trying to evade your enemies or if it's full pitched battle." (RGerbino 2002)

The authenticity of the sound effects has been commented upon by many critics, "Appropriately, the lightsabers, doors, guns and ships all make convincing vwings, shhps, fahtows and chughghs" (Butts 2002); "Every blaster shot, chirp, and squeak in the game is as authentic as it gets" (Torres 2001); "All the typical blaster sounds, ion engine whines and explosions that you are used to hearing have been included. Rogue Leader sounds great" (Stevenson 2001); "The sound effects are equally impressive, with each weapon sounding exactly like they should" (Majaski 1997).

Where relevant, the quality of the voice acting has also been praised, especially where the original actors have been coaxed back to lend their vocal talents, "Factor 5 actually rustled up actor Denis Lawson, who played Wedge in the movies, to provide in-game voice" (Torres 2001). Yet, the presence of the actors featured in the films is not a prerequisite; rather, superior voice acting, as with any game, 
helps ensure that the corresponding characters are believable and engaging, "Hours of expertly done voice-over help make character interaction incredibly engaging throughout Knights of the Old Republic" (Kasavin 2003); "In fact, all of the voice acting is top notch-even the throwaway lines and little conversations within the missions are delivered well" (Butts 2002); "Voice actors do the entirety of the dialog in the game, and the voice acting is top-notch" (Stevenson 2003).

Inevitably, John Williams' score has received particular attention-and lavish praise-from critics, underlining the role these compositions play in ensuring the games feel like authentic Star Wars experiences, "One of the best parts of Jedi Knight is the music. It's spooled directly off the CD and is straight from the movies" (Majaski 1997). A pair of Dark Forces reviews further illustrate the reverence for Williams' score:

"The music is unbelievably good, having been composed by John Williams and drawn exclusively from 20 years' worth of commissioned work for the Star Wars trilogy. The result is a score that succeeds at covering the entire spectrum of a grand adventure story; it is a lush, suspenseful and heroic body of work." (Campbell 1999)

The Adrenaline Vault review, in which the author suggested that "if I could give the Musical Score category more than 5 Stars, I would", describes how the familiar musical motifs enhanced their gameplay experience:

"The first thing the devoted Star Wars fan will notice regarding the music is that the actual John Williams score is used throughout the game. There were times that the "Imperial March" theme would begin playing as I entered a new area, and I became worried that something was hanging around the next corner for which I might not be prepared!" (Brumbaugh 1997)

This near-Pavlovian response to the games' musical cues is further explained by Josh Campbell, writing for Gamezilla:

"I suppose it should be pointed out that to some people, especially those who are roughly my age and have had this music burned into their gray matter since their formative years, it simply means adventure the same way a red light means Stop." (Campbell 1999)

Several titles have successfully supplemented Williams' work with original compositions:“During [Rogue Squadron II], the soundtrack alternates between known pieces of music from the films, as well as original music from the game, adapting and blending on the fly" (Torres 2001). However, it is notable that reviews for the venerable Knights of the Old Republic (KOTOR) have contained certain heretical statements, which imply Williams' compositions are not an essential feature of a Star Wars adaptation:

"Some of the audio is what you'd expect from a Star Wars game, though Knights deserves credit for featuring a mostly original (yet very subdued) soundtrack, which is a nice change of pace from the ubiquitous John Williams score." (Kasavin 2003)

And, indeed:

"While all the Star Wars-related sound effects are here, Bioware chose not to use the John Williams score. This is a good thing, because very little of this game has anything to do with the movies. The score is absolutely excellent, and is perfect in the game." (Stevenson 2003)

KOTOR is not entirely bereft of Williams' motifs-the opening crawl, featuring the classic fanfare is present and correct-but the game was almost wholly scored by The Elder Scrolls composer, Jeremy Soule. Thus, the best-reviewed Star Wars game considered here is that which features the lowest proportion of the film composer's seminal score. That said, KOTOR is noteworthy for its length: players can expect to spend perhaps $40 \mathrm{~h}$ completing BioWare's opus, while a title such as Rogue Squadron II may be completed in less than a quarter of that time. KOTOR is also the least direct adaptation of the movies considered here: as the Cinescape review pointed out, the game has little to do with any of the 
films and the inclusion of themes associated with particular characters (Leia's Theme, Yoda's Theme, the Imperial March) would be nonsensical. With nearly two days' worth of action to score, and a story that predates the events of the original movies by at least a couple of millennia, it is clear why BioWare looked beyond Williams' body of work in this instance. Perhaps KOTOR is the exception which proves the rule that a good Star Wars game must make liberal use of John Williams' orchestrations.

\section{Control, Control! You Must Learn Control!}

Gameplay is a broad and somewhat elusive term, for which there are no convenient analogues in cinema: while the audio-visual qualities of both video game and film may be assessed using somewhat congruent terminology, the interactive nature of the former medium requires an alternative vocabulary. Gameplay may comprise everything from the nature of player interactions to the design of the challenges that players will face, including the underlying rules and systems. It may also refer to the feel of the game in the player's hands, and it is this aspect-how the games are controlled-that we examine next. Consider the following excerpt from the Cinescape review of Rogue Leader:

"What better way to toss gamers into the action than to start you off on the attack on the first Death Star? You could, of course, take a training run in a T-16 Skyhopper, but what's the fun in that? Actually, the trial run isn't really necessary; the controls are top-notch." (Stevenson 2001)

Some discussion of the games' controls-here described as "top-notch" —is present in many of the reviews. But what constitutes a "top-notch" control scheme? The GameZone review of Rogue Leader related the quality of the controls to the feel of the movements they elicit:

“The controls are excellent. All of the movements feel just right-you never feel like something is out of place or that it doesn't belong. When you hop into an X-Wing, you're really hopping into an X-Wing!" (Bedigian 2001)

Eurogamer found the Rogue Leader controllers "over-responsive", suggesting that the "feel of the system conflicts with the game's principle virtue: its authenticity". However, IGN's analysis of the same game's controls was similarly based on the feel of the movement, and was entirely positive in its appraisal of how the ships handle:

"Flight control has overall seen significant improvements. The sway and reaction of ships is tighter and consequently more in tune with the movement of the crafts from the movies. Overall, ships handle fast and furious and the level of control is consistently tight and responsive." (Casamassina 2001)

Meanwhile, the GamePro review of Jedi Outcast identified lightsaber control—surely a fundamental feature of such a game-as the only weak spot in an otherwise satisfactory control scheme:

"You haven't done it all until you've fought two 'saber-wielding evil Jedi and defeated one with sheer skill before choking the other to death with the Force. Unbelievable. And ... surprise! It all controls rather well with only the chaos of the lightsaber duels to detract from a feeling of total control." (Darth Destroyer 2002)

While a game's controls can initially appear to be a mundane concern, it is apparent that this is an important factor to consider in relation to video game adaptations of Star Wars. The controls are the player's conduit, the means by which they may demonstrate mastery of the ships and weapons that are such essential features of Lucas' galaxy. If the handling of an X-Wing feels inauthentic, or the control of a lightsaber is clumsy in its implementation, the player experience is compromised.

As noted above, gameplay can encompass a great deal more than the control scheme offered by a game. It can also refer to the game mechanics, and this is where the reviews of Angry Birds Star Wars (Rovio Entertainment Oy 2012)-largely absent from the preceding analysis of the best Star Wars games' audio-visual accomplishments-offer some relevant insight. The gameplay mechanics on which the 
Angry Birds franchise is built are well-established: a series of deceptively simple challenges, wherein the player must fling ill-tempered birds at the blocky structures erected by their mortal enemies, in order to destroy them. These mortal enemies are pigs, for ... reasons. Easily dismissed as a mere "casual" game, Angry Birds has not only proven popular enough to spawn its own spin-offs, movies, and merchandise, it has also garnered praise for its surprisingly deep and engaging gameplay. It is on these foundations that the Star Wars iteration of the franchise built and, according to the critics, it does so admirably. Indeed, the critical consensus is that the addition of characters and weapons inspired (however loosely) by the Star Wars movies only enhances the series' winning gameplay-as exemplified by the Game Informer review of the game:

"Gravity remains the weapon of choice to crush the evil Pig Empire, but the birds can also tap into the Force to magically move objects, swing lightsabers to cut through debris, and volley laser fire to take out multiple pigs at once. These new mechanics fit nicely with the series' well-established slingshot gameplay, and are tapped to create a variety of strategy-intensive levels that are among the most challenging and rewarding I've seen in an Angry Birds game." (Reiner 2012)

Writing in The Guardian, Stuart Dredge agreed, suggesting that the addition of the space saga's tropes "moves the Angry Birds gameplay on a notch, particularly when lasers are involved" (Dredge 2012). Likewise, the Polygon review described how the judicious incorporation of the Force-a concept so quintessentially Star Wars_creates further bird-based gameplay possibilities:

“The Force also serves the enemy pigs. Darth Vader-pig levitates platforms in certain stages, and taking him out releases the objects, raining down on helpless Empire-pigs. The Force isn't just a gimmick in Angry Birds Star Wars, it's a layer of strategy." (Plante 2012)

In much the same way that the Angry Birds adaptation of Star Wars advanced an existing gaming franchise, there are further indications that the best Star Wars games can further refine and expand upon established gaming genres. Praising the "ingeniously designed" levels, the Gaming Age review of Jedi Knight labelled the game "one of the greatest first-person action/adventure games ever made", before concluding that "this game redefines the genre" (Majaski 1997). Describing the gameplay as Jedi Outcast's "real star", the GamePro review of that game suggested that "adding Jedi powers to an already-great FPS [first-person shooter] engine is a stroke of genius" (Darth Destroyer 2002). In doing so, the developers opened up new game design possibilities that enliven the already crowded FPS genre:

"Playing Jedi Outcast is a pleasure in and of itself. Raven has displayed great creativity in this title, especially in level layout and puzzles. The Force powers gave the developers a lot of leeway in what they could do with puzzles, and by and large, the challenges you'll face are more than your average push-box-jump-over-chasm FPS puzzles." (Darth Destroyer 2002)

Other innovations identified in the very best Star Wars games include KOTOR being bestowed the title of "the first successful Western-style console Role-Playing Game [RPG] of the modern age" by Eurogamer, on the basis that it "takes the design beliefs of the Western RPG form and then works out how to present them best for playing whilst sprawled on a sofa in your living room" (Gillen 2003). KOTOR, with its novel dark side/light side mechanic, also paved the way for so-called 'karma' systems in subsequent video game blockbusters, such as Mass Effect (BioWare 2007):

"Knights lets you play as a really nasty character if you so choose, and that's certainly part of the fun. It's also an interesting aspect of gameplay, considering a big part of the theme is how Jedi constantly run the risk of falling to the dark side-indeed, you'll probably often be tempted to see what happens if you pick the evil dialogue options rather than the good ones, if only because most RPGs simply don't let you make these types of decisions. Certain key points in the game will play out very differently depending on the decisions you make, creating lots of replay value." (Kasavin 2003) 


\section{You Have No Place in This Story. You Come from Nothing. You Are Nothing. But Not to Me}

While, in some instances, video games may be bereft of any meaningful story, narrative is an important aspect of many titles. A compelling plot might serve to enrich the player experience through the Aristotelian complications, reversals, and revelations that may underpin any dramatic narrative. Or a story may serve simply as a means of tying together the action, a narrative justification for the next round of puzzle solving or wanton destruction.

When it comes to video game adaptations of another narrative form, however, perhaps it is especially important to consider the qualities of the story. Certainly, this is an aspect that many of the reviews of these games have touched upon, to varying degrees. The GameZone review of Star Wars Jedi Knight II: Jedi Outcast, for example, merely noted that "the storyline is gripping" (RGerbino 2002). Reviewing that same game, the IGN review was more specific in its praise:

"Everything is tied together with a tightly written, mature plot. Kyle's motivations and the progression of the story are all handled with a touch that is at once both subtle and unrelenting. There's a nice balance and sense of pace here." (Butts 2002)

Meanwhile, several critics have remarked upon the perfunctory but perfectly adequate nature of the games' attendant story. In the Gamezilla review of Jedi Knight: Dark Forces II (LucasArts Entertainment Company LLC 1997), for example, Josh Campbell described the tale of vengeance that drives the game's narrative, noting that such a tale is "not exactly complex or intriguing on its own, but suitable enough to frame a video game around" (Campbell 1999). Similarly, the Gamespot review of Dark Forces II was somewhat critical of the "cliched" storyline but conceded that "it does a fine job of providing links between the levels" (Dulin 1997). Elsewhere, another Gamespot review—concerning Rogue Squadron II-offered nothing but praise for the "much more tightly focused" story that connects each of that game's levels, noting that "the tighter narrative complements the missions and makes for an extremely cohesive and satisfying experience, as every mission flows very naturally into the next" (Torres 2001).

Other critics, however, waxed lyrical about the narrative elements of the game in question. In Craig Majaski's review of Jedi Knight: Dark Forces II, for example, the game's storytelling was described in revered, overtly cinematic terms:

"One of the crucial elements that separate Jedi Knight from the rest of the overcrowded PC gaming market is its story. At the beginning of the game and between each level you'll be treated to cinema scenes. These mini-movies are extraordinarily done and help propel the story along through its twists and turns." (Majaski 1997)

Meanwhile, the Gamespot review of Knights of the Old Republic suggested that tales of the conflict between the light side and the dark—as captured in that game's unique mechanics-are intrinsic to the franchise:

"The game's greatest accomplishment is its focused yet open-ended plot progression, which gives you the freedom to play as either a morally good or evil character, or shades in between. The struggle between good and evil is of course central to Star Wars and manifests itself extremely well throughout this outstanding game." (Kasavin 2003)

This perceived freedom is limited in nature, usually reducing the player's options to one of two binary choices or a single, middling option; in truth, player agency is restricted by the algorithmic constraints of the game's programming. MacCallum-Stewart and Parsler (2007) termed this figment of freedom "illusory agency", noting that game designers "can seek to grant as much freedom as they can or they can seek to disguise the fact that possible actions are limited", in order to convince the player that their choices matter. Wardrip-Fruin et al. (2009) further refined the notion of agency in games "as a phenomenon, involving both the game and the player, that occurs when the actions players desire are among those they can take as supported by an underlying computational model". This definition perhaps better accounts for the perceived open-endedness of KOTOR's plot: the narrative choices 
offered to players are constrained by the game's "computational model", but such constraints are of little consequence when they align sufficiently with the player's intentions for their character.

An important component of any story is the characters that bring it to life, and this holds true for the Star Wars adaptations considered here. Writing for Eurogamer, Kieron Gillen noted the care with which the (nonplayer) characters in Knights of the Old Republic have been developed:

"Far more interesting is how these characters are turned into actual characters-an all the more powerful blow aimed at the heart. Beautifully written, carefully defined and memorable, this is a cast who engender sympathy and empathy. Everyone in the world will fall in love with Assassin/Translator droid HK-47 (In short: Imagine if C-3P0 was a misanthrope who wanted to kill everyone), but you'll all find personal favourites." (Gillen 2003)

In his Gamespot review of the same game, Greg Kasavin suggested that "character interaction really is the best thing about Knights of the Old Republic", while "the game's main storyline isn't remarkable and eventually boils down to squaring off against your standard bad guy" ${ }^{\prime 3}$. Nonetheless, according to Kasavin, the player will "encounter so many great little subplots and characters along the way that this really won't matter" (Kasavin 2003). Expanding on the importance of well-developed characters, Kasavin also described how meaningful character interaction elevates the experience:

"You'll always be an active participant in the storyline, rather than a passive observer. You don't just read, watch, and listen to a lot of text, cutscenes, and dialogue-your character is constantly invited and required to make difficult decisions, and that's ultimately the most entertaining, impressive, and rewarding aspect of the game." (Kasavin 2003)

Star Wars, as a franchise, has a long association with transmedial storytelling (see Guynes and Hassler-Forest 2018) with video games playing a significant role in expanding the Star Wars storyworld, or the larger "narrative universe" (Mejeur 2018). All of these stories take place within a shared world, although Ryan — citing Star Wars as an example-suggested there is a distinction to be made between cases in which "they represent the same world and in which cases they project related but distinct worlds" Ryan (2014, p. 42). Regardless of whether the storyworld presented in a Star Wars game might be considered part of the same canonical universe as the movies ${ }^{4}$, players nonetheless benefit from what Jenkins has termed "additive comprehension" Jenkins (2006, p. 123). That is, players' enjoyment of these games is enhanced by their prior knowledge of the Star Wars storyworld.

\section{It Will Be Just Like Beggar's Canyon Back Home}

As we have seen, much of the commentary on the games' audio-visual qualities has related to the degree to which the games look and sound "just like the movies". Some of the more enthusiastic comments include GameZone's Louis Bedigian, who said of Rogue Leader, "Enter the battlefield (or should I say 'enter the movie'?) and prepare to be blown away again" (Bedigian 2001). The Eurogamer review of that game was similarly effusive ("Rogue Leader is Star Wars the way you remember it") while the IGN review noted, "Rogue Leader sounds like Star Wars. Perfectly" (Casamassina 2001).

Indeed, discussion of the games' faithful reproduction of the movies has often been intertwined with admiration for the technical adroitness on display:

"The game plays out like the movie, with Luke running interference over the Death Star and eventually flying down the trench. There's no slowdown, tons of fighters on screen, and an incredible sense of speed." (Stevenson 2001)

3 One could argue, of course, that the Star Wars movies frequently boil down to confronting a "standard bad guy", as is befitting of a story inspired directly by myths that typically culminate in such a confrontation.

4 This is a question made all the more complicated by the transmedial strategy embarked upon by Disney following their acquisition of the Star Wars property-see (Brown 2019). 
The GameZone review of Jedi Outcast also praised the technical artistry that brings the game's characters to life with greater fidelity than was, at that time, previously possible to achieve:

"I have never seen the Star Wars universe recreated with such attention to detail. This game is the closest thing we have to actually living inside the film. Each character model is so well done and I even found the cut scenes interesting." (RGerbino 2002)

Noting that Rogue Leader "represents the closest recreation of the Star Wars universe that we have yet to see", however, the IGN review of that game acknowledged that the technology was simply a means to an end:

"But none of these tech feats mean anything to the end player. What matters is that all of these effects come together to quite realistically mimic the real thing-and that's an accomplishment that is close to monstrous." (Casamassina 2001)

Frequently alluded to by critics is the idea that the best Star Wars adaptation are capable of immersing the player in this familiar but fantastic world, "The way it submerges you in George Lucas' universe and takes you on a wild ride is unmatched" (Stevenson 2001). For Gamespot's Greg Kasavin, this sense of immersion extended to feeling as though the player is a part of this world:

"It's one of the only Star Wars games to truly make you feel at times as though you're a key player in and a part of this unique and beloved sci-fi setting. You'll get to do all the sorts of stuff that you've seen and enjoyed in the Star Wars movies, and you'll get to emulate any of your favorite characters' personalities and actions over the course of the game." (Kasavin 2003)

The concept of immersion has proven surprisingly slippery in game studies. In the seminal Hamlet on the Holodeck, Janet Murray referred to immersion as "the experience of being transported to an elaborately simulated place", comparing this experience to "a plunge in the ocean or swimming pool" Murray (1997, p. 98). However, McMahan usefully differentiated between the frequently conflated terms immersion and presence, the latter being defined as "the feeling of being there" McMahan (2003, p. 68). While care must be taken not to ascribe unintended meaning to reviewers' words, it seems reasonable to assume that it is the feeling of being in the Star Wars universe-the feeling of presence - that underpins much of the appeal of these adaptations. Indeed, each of the dimensions of presence in video games conceptualised by Tamborini and Bowman (spatial presence, social presence, and self-presence) may be identified in the reviews considered here Tamborini and Bowman (2010, pp. 88-89).

Several reviews have alluded to the joy of the familiar, as we have already seen in the discussion of the games' audio and video. The game designers were, of course, leveraging players' familiarity with the characters, ships, and locations to ensure that the games feel like Star Wars, a point not lost on Craig Majaski in his review of Dark Forces II:

"If the familiar locales aren't enough to get you into the Star Wars universe, the different enemies from the movies are here in full force to remind you. You'll recognize many of the characters and vehicles. From Stormtroopers and R2 Units to the AT-ST and Tuskens, you'll be pleased to know they're all in here." (Majaski 1997)

The IGN review of Rogue Leader made a similar point, but also offered praise for the noncanonical scenarios created specifically for the game:

"Each scenario is overflowing with Star Wars character. The Attack on the Death Star, which we mentioned above, is somewhat of a dream come true for many fans as it perfectly re-creates the experience from the film. But there are of course many other areas to explore and battle through, each just as appealing." (Casamassina 2001) 
This suggests that successful Star Wars adaptations are not necessarily constrained by the movies and, as noted above, arguably the best-regarded video game adaptation of the saga, Knights of the Old Republic, largely eschewed its celluloid progenitors. Reviewing KOTOR for Gamespot, Greg Kasavin was keenly aware of the advantages of doing so, "Knights arguably lives up to the Star Wars name better than any other Star Wars property in years, including the last two theatrical films" (Kasavin 2003). Kieron Gillen's Eurogamer review neatly summarised how KOTOR succeeds while maintaining a studied distance from the movies, touching upon the idea that the mythic structure of the story is sufficiently familiar to conjure up the feel of Star Wars:

"It feels more like Star Wars than anything else has in living memory, and does so by moving the focus back four thousand years. And-would you believe it—things are very much as they are in the "contemporary" Star Wars universe. This gives the game the strength of familiarity of theme, a mythic arc as you realise you're rooting around in the prehistory of the world and due to distance from the actual films, freedom to create a plot as galaxy-spanning as anything that was committed to celluloid." (Gillen 2003)

In many cases, critics directly commented on the quality of the adaptation, as in the IGN review of Rogue Leader, "It's taken more than 20 years, but a development studio has finally captured the spirit and beauty of the Star Wars trilogy movies and crammed it all into one action-packed game" (Casamassina 2001). The relationship between the game and the original source material was also considered in the Eurogamer review of Rogue Leader:

"We often compare games to movies, but from the archetypal star screen introduction right the way through to the game's monumental climax, this is the ultimate accompaniment and tribute to those three original Star Wars movies we all cherish." (Bramwell 2002)

Meanwhile, the GameSpot review of Dark Forces II rather downplayed the challenge of adapting the beloved franchise into a video game:

"Designing a game set in the Star Wars universe seems like a no-brainer. The look and sounds of the game-from the Imperial gray of walls, to the elephantine squeal of a TIE Fighter engine, to the squeaky "pew, pew" of a blaster shot-are already set in stone, so designers just need to think of a genre and use the existing elements to build a game." (Dulin 1997)

Still, as the swathes of substandard movie tie-ins clearly demonstrate, creating a good game based on a movie is not so straightforward. As alluded to in the GamePro review of Jedi Outcast, a glut of relatively poor Star Wars games were released around the turn of the century, from Masters of Teräs Käsi (LucasArts 1997) to Flight of the Falcon (Pocket Studios 2003):

“Bucking recent trends in Star Wars gaming, Star Wars Jedi Knight II: Jedi Outcast is good. Really good. It's a balance of license and gameplay that brings honor to the Star Wars name and real Jedi action to your PC." (Darth Destroyer 2002)

Certainly, the presence of the Star Wars license alone is no guarantee of quality, as unfortunate owners of the blatant cash grab known as Attack of the Clones for the Gameboy Advance will attest. Thus, as the Polygon review of Angry Birds Star Wars made clear, expectations were not generally high when news of this unholy alliance emerged:

"Such a high-profile combo may trigger a gag reflex in the throats of gamers and Jedi alike, and understandably so. Both have been thoroughly spurned by insipid tie-ins and cash grabs. But Rovio's latest flies to the tender core of such cynicism and blasts it to stardust, with a payload of creativity, playfulness and reverence for the beloved sci-fi classic." (Plante 2012)

The Guardian review of the Angry Birds spin-off expressed similar reservations, before concluding that Angry Birds Star Wars is simultaneously the best entry in the Angry Birds franchise, and the best Star Wars adaptation in some time: 
“... Scepticism about such a partnership is understandable: when the world's biggest entertainment brand ever meets the most popular brand of the mobile apps era, the danger is compromise: a game so hemmed in by brand guidelines that it forgets to be fun." (Dredge 2012)

As many of the critics cited here have implied, a good Star Wars adaptation must first and foremost be a good game. For example, the IGN review of Jedi Outcast suggested that "not only is this one of the greatest Star Wars games I've ever played, it's one of the best action games period" (Butts 2002), meanwhile, the Gamespot review of KOTOR made a similar point, "Knights is both an outstanding RPG in its own right and an excellent tribute to the Star Wars source material" (Kasavin 2003). Referring to LucasArts' early 1990s heyday, when Lucasfilm's games studio offshoot was casually churning out classics such as The Secret of Monkey Island (Lucasfilm Games 1990), Indiana Jones and the Fate of Atlantis (LucasArts 1992), and, of course, Star Wars: X-Wing (LucasArts Entertainment Company LLC 1993), Keiron Gillen had this to say in his KOTOR review:

“The irony is before LucasArts lost anyone with a designer's brain in the company, they made some frankly astonishing videogames [ ... ] Because I love videogames, I love the great Star Wars games that came from this period, because they're great videogames-not because they're from that Galaxy a Long, Long way away." (Gillen 2003)

Stating that "some games don't need a license to be good", the Eurogamer review of Rogue Leader emphatically refuted the idea that players are blinded by the application of a veneer of Lucas' magic to an otherwise unremarkable game:

"Some have said that it wouldn't be as good without the Star Wars aspect, that it's a fairly mediocre space combat game, but to me that's a ridiculous argument. Rogue Leader is the embodiment of Star Wars in a videogame. That is the point." (Bramwell 2002)

The Game Informer review of Angry Birds Star Wars made a similar claim, suggesting that the spin-off is the series' best, "and that's not just because it's Star Wars" (Reiner 2012). According to Reiner, the introduction of elements lifted from the movies has enhanced the game, resulting in "the series' most creative levels to date". The flip side of this argument is that the (over)use of familiar Star Wars tropes can actually harm a game, as illustrated by this excerpt from IGN review of Jedi Outcast:

"The game's actually prompted a few discussions around the office about the use of licenses within games. [ ... ] the game uses a lot of the conventions (clichés if you're on the other side of the argument) of the movies. I tend to think you're sort of expected to know that going in. I mean, what's a Star Wars game without a garbage masher level?" (Butts 2002)

\section{Wars Not Make One Great!}

So, what does make a Star Wars video game adaptation truly great? There is little doubt that the aesthetic qualities of a Star Wars game are an important consideration: in keeping with the movies on which they are based, the video game adaptations are generally expected to provide audio-visual spectacle. But, more than this, the sounds and images serve to conjure up memories of the films, as so many of the reviews considered here have suggested. Music, in particular, is known to evoke strong emotions, and strong emotional responses are apt to form into powerful memories. Humans also have an innate capacity to mentally encode images and recall memories associated with imagery much more efficiently than those encoded as text. This is unsurprising, since we have used pictures to convey meaning for many millennia longer than we have used the written word to capture our thoughts. The deployment of familiar sounds and imagery, then, is undoubtedly vital to any video game adaptation that seeks to evoke our memories of the movies on which they are based.

However, while there is evidence here to support Brown and Krzywinska's assertion that critics place the greatest emphasis on games' audio-visual qualities Brown and Krzywinska (2009, p. 92), it is also apparent that many critics consider story to be an important aspect of any Star 
Wars adaptation. Somewhat unexpectedly, adherence to the plot of the original movies is identified as a positive in several reviews of Angry Birds Star Wars, for example, with the Game Informer review noting that "the biggest surprise in Angry Birds Star Wars is its faithfulness to Star Wars' story. The game follows A New Hope's arc surprisingly well" (Reiner 2012). That the story elements of these adaptations should be privileged in this way this should not come as a surprise, however. The original movie's arc (and, to some degree the overall structure of the original trilogy) was very deliberately modelled on the hero's journey, as identified by Joseph Campbell in his seminal work, The Hero with a Thousand Faces (Campbell 1949). In fact, Lucas has often referred to Campbell's influence on the development of his space saga, describing the academic's 1949 book as having a "wonderful life force" (Henderson 1997, p. 7). However, in defining the structure of the journey undertaken by the archetypal hero in myth, Campbell's work is not only ingrained in Star Wars, but also in how video games tell stories. The hero's journey, or monomyth, is a well-worn template for game writers and, while such a formulaic approach to the creative process has its detractors, some version of Campbell's monomyth continues to be taught to aspiring game designers. In Andrew Rollings and Ernest Adams on Game Design (Rollings and Adams 2003), for example, the authors distil Campbell's original 17-step journey down to a more manageable and generalisable nine. There is the call to adventure, the meeting with a mentor, and an assortment of "test, allies and enemies", culminating in a final ordeal: all of the key elements of Campbell's journey are present in, and readily applied to, the narrative structure of a game. George Lucas' galaxy is also populated by archetypes other than the hero. Like Campbell, Lucas has drawn heavily on the works of analytical psychologist Carl Jung, who identified a number of archetypal forms that he claimed were embedded in our collective unconscious. This shared understanding, buried in humans' unconscious mind, is also where Campbell's notion of the monomyth is also said to reside. It is possible, then, for the Star Wars movies and their ludic offspring to share a mythical ancestry, where the family resemblances are not merely aesthetic but, instead, relate to the underlying nature of the story being told. This may partially explain how a game such as Knights of the Old Republic, set thousands of years prior or the original film, can feel like Star Wars without slavishly recreating every celluloid story beat. Clearly, not every game that borrows from Campbell's monomyth is related to Star Wars-far from it. However, a Star Wars adaptation that draws upon the same archetypal themes as the films seems more likely to evoke the essential qualities of the source material.

The question then arises of whether direct adaptations (including Angry Birds and portions of the Rogue Squadron games) or titles that merely take inspiration from the films (such as Knights of the Old Republic) fare best. Brown and Krzywinska, for example, confidently stated that "the best movie-games are able to communicate something new about their parent texts on a thematic level, rather than simply parroting the events of the film" Brown and Krzywinska (2009, p. 93). And yet, with so many well-received Star Wars games featuring a recreation of the famous Death Star trench sequence from the original movie, including the 1983 arcade cabinet, Super Star Wars, and Rogue Squadron II, one could be forgiven for thinking that this scene alone was essential to the Star Wars video game experience. Indeed, Morton (2018) used the many ludic recreations of the trench run scene to examine the possibilities for transmedia play in Star Wars adaptations, arguing that "transcribing the Death Star trench run from $A$ New Hope to one of the many video games it appears in changes its meaning: the importance of the event is gleaned from one's knowledge of the film" Morton (2018, p. 106). Thus, even this most direct adaptation of one of the most recognizable scenes from the movie is altered in its translation to video games form. Indeed, as Sommerfeld (2012) noted, many of the "direct" adaptations-such as the Super Star Wars titles that corresponded to each of the original trilogy films-take serious liberties with the source material. Can a title in which Luke single-handedly takes down a Sarlacc pit monster even be considered a direct adaptation of the original film?

Meanwhile, Angry Birds Star Wars arguably hews closer to the source material, at least in terms of story structure, than many other adaptations-but is it adherence to the template Lucas laid down in the 1977 movie that sets this small screen blockbuster apart? Probably not, given critics' insistence that the Star Wars license alone is no guarantee of quality. Certainly, games that aim to recreate specific 
films - the much-maligned movie tie-ins—are amongst the worst reviewed titles of all. Meanwhile, the very best Star Wars games appear to be those that advance the state of the art, be it in redefining the Western RPG, as in the case of KOTOR, or elevating a previously successful genre to new heights, as with Angry Birds Star Wars. Perhaps this is why a game like Fallen Order fails to make the critical cut: with gameplay borrowed directly from other game franchises (Uncharted, Dark Souls), maybe Electronic Arts' most recent adaptation is simply too derivative to be distinctively Star Wars. But this is where the delineation between an excellent game and a superior adaptation becomes problematic: is a faithful reproduction of the Star Wars universe more important than engaging gameplay or novel game mechanics?

Perhaps, given the critical failure of the final entry in the cinematic Skywalker saga, it is fitting that now, at the very end, we return to the dismally received Game Boy Advance adaptation of Attack of the Clones. What this game demonstrates-perhaps more so than any other in the Star Wars (ion) canon-is that the ability to use the license is insignificant next to the power of good gameplay when it comes to adapting Star Wars. The truth is, the qualities of a great Star Wars game are largely the same as those of any great video game.

Funding: This research received no external funding.

Acknowledgments: Thank you to Eva Barr for her fastidious proofreading.

Conflicts of Interest: The author declares no conflict of interest.

\section{References}

Apperley, Thomas, and Darshana Jayemane. 2012. Game Studies' Material Turn. Westminster Papers in Communication and Culture 9: 5-25. [CrossRef]

Apperley, Thomas, and Jussi Parikka. 2015. Platform Studies' Epistemic Threshold. Games and Culture 13: 349-69. [CrossRef]

Bedigian, Louis. 2001. GameZone.Com-Star Wars Rogue Squadron II: Rogue Leader Review—GameCube Game. GameZone. December 6. Available online: https://web.archive.org/web/20030216231147/http: //gamecube.gamezone.com/gzreviews/r18631.htm (accessed on 8 December 2020).

BioWare. 2007. Mass Effect. Redmond: Microsoft Game Studios.

BioWare Austin, LLC. 2011. Star Wars: The Old Republic. Windows. Redwood City: Electronic Arts, Inc.

BioWare Corporation. 2003. Star Wars: Knights of the Old Republic. Xbox. San Francisco: LucasArts.

Bogost, Ian, and Nick Montford. 2007. New Media as Material Constraint: An Introduction to Platform Studies. Paper presented at the First International HASTAC Conference, Duke University, Durham, NC, USA, April 19-21; pp. 176-93.

Bramwell, Tom. 2002. Star Wars Rogue Squadron II: Rogue Leader. Eurogamer (blog). May 9. Available online: https://www.eurogamer.net/articles/r_rogueleader (accessed on 8 December 2020).

Brown, Douglas. 2019. To Disney Infinity and Beyond - Star Wars Videogames Before and After the Lucasarts Acquisition. In Disney's Star Wars: Forces of Production and Promotion. Iowa: University of Iowa Press, pp. 123-35. Available online: https://www.uipress.uiowa.edu/books/9781609386436/disney\%E2\%80\%99sstar-wars (accessed on 8 December 2020).

Brown, Douglas, and Tanya Krzywinska. 2009. Movie-Games and Game-Movies: Towards an Aesthetics of Transmediality. In Film Theory and Contemporary Hollywood Movies. Edited by Warren Buckland. AFI Film Readers. New York: Routledge.

Brumbaugh, Jim. 1997. Jedi Knight: Dark Forces II-Adrenaline Vault Featured Game. Adrenaline Vault. October 14. Available online: https://web.archive.org/web/19971014050458/http://www.avault.com/featured/jedi_ knight/review.asp (accessed on 8 December 2020).

Butts, Steve. 2002. PC Games: Star Wars Jedi Knight II: Jedi Outcast Review. IGN. April 1. Available online: https://web.archive.org/web/20030802190624/http://pc.ign.com/articles/356/356503p1.html (accessed on 8 December 2020).

Campbell, Joseph. 1949. The Hero with a Thousand Faces. New York City: Pantheon Books. 
Campbell, Josh. 1999. Jedi Knight: Dark Forces II. Gamezilla. October 12. Available online: https://web.archive.org/ web/20020617010912/http://www.gamezilla.com/review.aspx?review=7512 (accessed on 8 December 2020).

Casamassina, Matt. 2001. Star Wars Rogue Squadron II: Rogue Leader-IGN. IGN. November 16. Available online: https:/uk.ign.com/articles/2001/11/16/star-wars-rogue-squadron-ii-rogue-leader (accessed on 8 December 2020).

Darth Destroyer. 2002. Star Wars Jedi Knight II: Jedi Outcast Review for PC on GamePro.Com. GamePro. March 27. Available online: https://web.archive.org/web/20040811092324/http://www.gamepro.com/computer/pc/ games/reviews/22041.shtml (accessed on 8 December 2020).

David A. Palmer Productions. 2002. Star Wars: Episode II-Attack of the Clones. Game Boy Advance. Calabasas: THQ Inc.

Dredge, Stuart. 2012. Angry Birds Star Wars-Review. The Guardian. November 8. Available online: https://www.theguardian.com/technology/appsblog/2012/nov/08/angry-birds-star-wars-review (accessed on 8 December 2020).

Dulin, Ron. 1997. Jedi Knight: Dark Forces II Review for PC at GameSpot. GameSpot. October 9. Available online: https://web.archive.org/web/20030620103107/http://www.gamespot.com/pc/ action/jediknightdarkforces2/review.html (accessed on 8 December 2020).

Electronic Gaming Monthly. 2002. 'Star Wars Episode II: Attack of the Clones'. Electronic Gaming Monthly, July 12.

Factor $5 \mathrm{GmbH}$. 1998. Star Wars: Rogue Squadron. Windows. San Francisco: LucasArts Entertainment Company LLC.

Foxman, Maxwell, and David B. Nieborg. 2016. Between a Rock and a Hard Place: Games Coverage and Its Network of Ambivalences. Journal of Games Criticism 22. Available online: http:/gamescriticism.org/articles/ foxmannieborg-3-1 (accessed on 8 December 2020).

Gillen, Kieron. 2003. Star Wars: Knights of the Old Republic. Eurogamer (blog). September 12. Available online: https://www.eurogamer.net/articles/r_starwarskotor_x (accessed on 8 December 2020).

Guynes, Sean, and Dan Hassler-Forest, eds. 2018. Star Wars and the History of Transmedia Storytelling. Amsterdam: Amsterdam University Press, Available online: https://www.degruyter.com/view/title/543353 (accessed on 8 December 2020).

Henderson, Mary. 1997. Star Wars: The Magic of Myth. New York: Bantam Books.

Hutton, Margaret-Anne, and Matthew Barr. 2019. Introduction: A Literary Studies/Games Studies Conversation. Games and Culture 15: 751-56. [CrossRef]

Jenkins, Henry. 2006. Convergence Culture: Where Old and New Media Collide. New York: New York University Press.

Kasavin, Greg. 2003. Star Wars: Knights of the Old Republic. GameSpot. July 15. Available online: https://web.archive.org/web/20030718100036/http://www.gamespot.com/xbox/rpg/ starwarsknightsoftor/review.html/ (accessed on 15 December 2020).

Lucas, George. 1999. Star Wars: Episode I-The Phantom Menace. Los Angeles: 20th Century Fox.

Lucasfilm Games. 1990. The Secret of Monkey Island. San Francisco: Lucasfilm Games.

LucasArts. 1992. Indiana Jones and the Fate of Atlantis. San Francisco: LucasArts.

LucasArts. 1997. Star Wars: Masters of Teräs Käsi. PlayStation. San Francisco: LucasArts.

LucasArts Entertainment Company LLC. 1993. Star Wars: X-Wing. PC. San Francisco: LucasArts Entertainment Company LLC.

LucasArts Entertainment Company LLC. 1997. Star Wars Jedi Knight: Dark Forces II. Windows. San Francisco: LucasArts Entertainment Company LLC.

LucasArts Entertainment Company LLC. 1999. Episode I: Racer. Windows. San Francisco: LucasArts Entertainment Company LLC.

LucasArts Entertainment Company LLC. 2000. Star Wars: Episode I Battle for Naboo. Nintendo 64. San Francisco: LucasArts Entertainment Company LLC.

LucasArts Entertainment Company LLC. 2001. Star Wars: Starfighter. PlayStation 2. San Francisco: LucasArts Entertainment Company LLC.

MacCallum-Stewart, Esther, and Justin Parsler. 2007. Illusory Agency in Vampire: The Masquerade—Bloodlines. Dichtung Digital 37: 142.

Majaski, Craig. 1997. PC Reviews-Jedi Knight. Gaming Age. Available online: https://web.archive. org/web/20041030151753/http://www.gaming-age.com/reviews/archive/old_reviews/pc/jedi/ (accessed on 8 December 2020). 
McMahan, Alison. 2003. Immersion, Engagement, and Presence: A Method for Analyzing 3-D Video Games. In The Video Game Theory Reader. Edited by Mark J. P. Wolf and Bernard Perron. London: Taylor \& Francis Group, pp. 67-86.

Mejeur, Cody. 2018. Chasing Wild Space: Narrative Outsides and World-Building Frontiers in Knights of the Old Republic and the Old Republic. In Star Wars and the History of Transmedia Storytelling. Edited by Sean Guynes and Dan Hassler-Forest. Amsterdam: Amsterdam University Press, pp. 199-210. [CrossRef]

Morton, Drew. 2018. "You Must Feel the Force around You!": Transmedia Play and the Death Star Trench Run in Star Wars Video Games. In Star Wars and the History of Transmedia Storytelling. Edited by Sean Guynes and Dan Hassler-Forest. Amsterdam: Amsterdam University Press, pp. 101-14. [CrossRef]

Murray, Janet H. 1997. Hamlet on the Holodeck: The Future of Narrative in Cyberspace. Cambridge: MIT Press.

Naremore, James. 2000. Film Adaptation. New Brunswick: Rutgers University Press.

Nieborg, David B., and Tanja Sihvonen. 2009. The New Gatekeepers: The Occupational Ideology of Game Journalism. 9. Available online: http://www.digra.org/digital-library/publications/the-new-gatekeepers-theoccupational-ideology-of-game-journalism/ (accessed on 8 December 2020).

Obsidian Entertainment, Inc. 2004. Star Wars: Knights of the Old Republic II-The Sith Lords. Xbox. San Francisco: LucasArts.

Plante, Chris. 2012. Angry Birds Star Wars Review: Great Shot, Kid. Polygon. November 8. Available online: https://www.polygon.com/2012/11/8/3615374/angry-birds-star-wars-review-great-shot-kid (accessed on 8 December 2020).

Pocket Studios. 2003. Star Wars: Flight of the Falcon. Game Boy Advance. Calabasas: THQ.

Ramsay, Debra. 2020. Liminality and the Smearing of War and Play in Battlefield. Game Studies. 20. Available online: http://gamestudies.org/2001/articles/ramsay (accessed on 15 December 2020).

Raven Software Corporation. 2002. Star Wars Jedi Knight II: Jedi Outcast. Windows. San Francisco: LucasArts Entertainment Company LLC.

Reiner, Andrew. 2012. Angry Birds Star Wars Review-A New Hope for Angry Birds. Game Informer. November 13. Available online: https:/www.gameinformer.com/games/angry_birds_star_wars/b/ios/archive/2012/11/ 13/angry-birds-star-wars-review-a-new-hope-for-angry-birds.aspx (accessed on 8 December 2020).

Respawn Entertainment LLC. 2019. Star Wars Jedi: Fallen Order. Various. Redwood City: Electronic Arts, Inc.

RGerbino. 2002. GameZone.Com—Star Wars Jedi Knight II: Jedi Outcast Review—PC Game. GameZone. April 8. Available online: https://www.gamezone.com/gzreviews/r18815.htm (accessed on 8 December 2020).

Rollings, Andrew, and Ernest Adams. 2003. Andrew Rollings and Ernest Adams on Game Design. Indianapolis: New Riders.

Rovio Entertainment Oy. 2012. Angry Birds: Star Wars. IOS. Espoo: Rovio Entertainment Oy.

Ryan, Marie-Laure. 2014. Story/Worlds/Media: Tuning the Instruments of a Media-Conscious Narratology. In Storyworlds Across Media: Toward a Media-Conscious Narratology. Edited by Marie-Laure Ryan and Jan-Noël Thon. Lincoln: University of Nebraska Press, pp. 25-49.

Sculptured Software, Inc., and LucasArts Entertainment Company LLC. 1992. Super Star Wars. Super Nintendo. Yokohama: JVC Musical Industries, Inc.

Siskel, Gene. 1977. 'Star Wars' Flashes with Space Wizardry. Chicago Tribune. May 27. Available online: https://www.newspapers.com/image/?clipping_id=39389179 (accessed on 8 December 2020).

Sommerfeld, Seth. 2012. Gaming in a Galaxy Far, Far Away: The History of the Expanded Worlds, Canon Conflicts, and Simplified Morality of Star Wars Video Games. In Myth, Media, and Culture in Star Wars: An Anthology. Edited by Douglas Brode and Leah Deyneka. Lanham: Scarecrow Press, pp. 124-34.

Stevenson, James. 2001. Cinescape-Home-Editorial. Cinescape. November 20. Available online: https://web.archive.org/web/20030904130748/http://www.cinescape.com/0/editorial.asp?aff_id=0\& this_cat=Games\&action=page\&type_id=\&cat_id=\&obj_id=31158 (accessed on 8 December 2020).

Stevenson, James. 2003. Cinescape-Home-Editorial. Cinescape. July 31. Available online: https://web.archive.org/web/20051201105200/http://www.cinescape.com/0/editorial.asp?aff_id=0\& this_cat=Games\&action=page\&obj_id=39277\&type_id=270331\&cat_id=270834\&sub_id=271912 (accessed on 8 December 2020).

Tamborini, Ron, and Nicholas D. Bowman. 2010. Presence in Video Games. In Immersed in Media: Telepresence in Everyday Life. Edited by Cheryl Campanella Bracken and Paul Skalski. London: Routledge, pp. 87-109. 
Torres, Ricardo. 2001. GameSpot: GameCube Reviews: Star Wars Rogue Leader: Rogue Squadron II Review. GameSpot. November 8. Available online: https://web.archive.org/web/20011120051714/http: //www.gamespot.com/gamespot/stories/reviews/0,10867,2823605,00.html/ (accessed on 8 December 2020). Wardrip-Fruin, Noah, Michael Mateas, Steven Dow, and Serdar Sali. 2009. Agency Reconsidered. In Proceedings of DiGRA 2009. London: Brunel University.

Publisher's Note: MDPI stays neutral with regard to jurisdictional claims in published maps and institutional affiliations.

(C) 2020 by the author. Licensee MDPI, Basel, Switzerland. This article is an open access article distributed under the terms and conditions of the Creative Commons Attribution (CC BY) license (http://creativecommons.org/licenses/by/4.0/). 